\title{
The Influence of Marxism on College Students' Values under Network Form
}

\author{
WangXiaofeng \\ Nanchang Institute of Science \&Technology,Nanchang 330108,China
}

Keywords: Marxism form; College students; Fixed-effect model; Estimate variance

\begin{abstract}
Marxism form is in contemporary form development and under the background of the times, whose rapid development becomes a form of expression, which has reflected people's value cognition system and ideology and Marxism form. It has gradually become the most important information sources, and its application scope expand very quickly. Related to a wide range of benefits, it comes from all walks of life and all aspects of life. As the use of the most active groups, the college students' cyber source also makes Marxism form to the campus gradually, which plays great influence on the values of university students.
\end{abstract}

\section{Introduction}

Marxism made a significant impact on current social form, harmful information continues to pour into the Marxism, today students relying more on Marxism, and express their feelings 、 attitude and notion by it and so on, so Marxism is an important factor of students' thought attitude and action[1]. There are much study on Marxism's form to college students' value ,such as Zhou Yonghua and Huang Jiaming's Marxism form's negative effects on today's college students and its countermeasures, mainly analysis two sides of Marxism's characteristics, art with Marxism's negative effects on college students, emphasize educatory of university's thought must try their best to reduce the harm negative effects for college students, and it can promote the development of college students' healthy; Kuang Yong's the influence of Marxism form on college students' values and its countermeasures, analysis Marxism's characteristic, the shock and influence of current students' value of their life under the characteristic, thus lead to depth thinking; Zhao Yiqun and SuJian's the influence of Marxism form on college students' core values and its countermeasure that underline college students' core value's opportunity and challenge by Marxism form , dialectically analysis influence factor of Marxism form ,thereby lead college students to building right values; Zhang Tongtong and Tian Ning's influence of Marxism form to college students' value and its countermeasures, analysis the students after 90s' characteristic, analyze the Marxism form's positive effect and negative effect , using Marxism information platform to lead college students to launch a positive Marxism cultural activities, customized carry out under socialism. Ji Zhenqiang's social Marxism form to college students' ideological and political education's influence and its countermeasure. Analyzes the current social Marxisming websites SNS's new social cultural characteristics, Analyzes social Marxism form's ideological and moral influence on college students[2]. Thus concluded that university guide social Marxism form's countermeasures of development, Ma Jun 's Marxism form's influence on college students' values and its countermeasures, From the situation of campus Marxism form, analysis all kinds of campus Marxism form, In view of its influence on the students to formulate relevant strategy, The university worker should make full use of Marxism form to lead students to form positive values effectively, training students' three reflections. 


\section{The empirical analysis of current Marxism form}

Part of the global Internet social Marxism's present using situation. In the past twenty years, information and communication technology influences and change our way of life and social relations largely, College students' chat, work or to participate in their recreational activities are closely related with the Marxism. Seven days a week, 24 hours a day, more or less they will spend some time in the Marxism that it is a virtual environment. According to the international telecommunication union's data, today's mobile Internet users has reached 2.1 billion, accounted for $30.9 \%$ of the global population. Although the Marxism coverage is relatively low at present, but this means that in the next few years, the number of global Internet users will maintain the rising trend. Royal Pingdom collect a large number of E-mail, web site, Marxism server, domain name, Internet users, social media, mobile and web browser's data from the global Internet industry development's reports in2015. Specific data is as below.

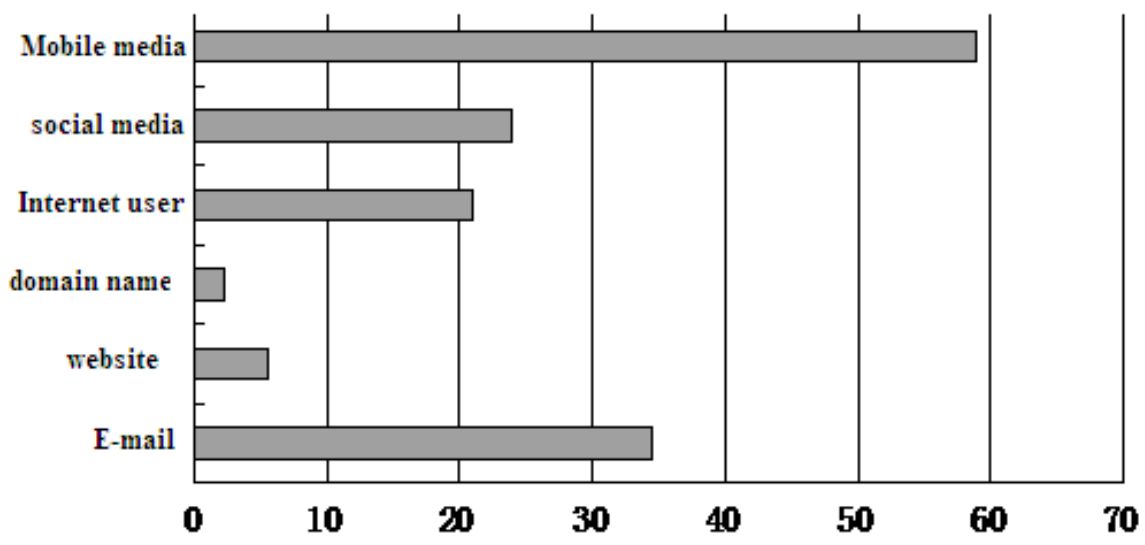

Fig. 1 The part of the social media of global Internet's data statistics

Figure 1 shows that global E-mail account's number is 3.46 billion; website's number are 555 million by the end of December2015, the number of registered domain name are 220 million by the end of the third quarter of 2015. The totaled number of global Internet users is 2.1 billion. Global social Marxism account's number are 2.4 billion. The number of mobile users are estimated at 5.9 billion in 2015. In the incomplete statistics, the world mobile Internet users' growth are proceeded at a great lick, based on the second generation of the Internet's developed applications, the elements of sharing, social and coordination is very attractive for Marxism user.

The present using situation of China's Internet users' social websites. From social Marxisming websites' application report of Chinese netizens in2015, the problems of most of China's netizens discussed on social Marxisming sites is the personal information, Share and discuss content of Chinese netizens in social Marxisming sites are shown below.

As Figure 1 shows, Chinese netizens in social Marxisming websites for individual personal life dynamic and mood feeling of exchange is $44.6 \%$; the percentage of engaged in entertainment (music, movies, sports)is $44.6 \%$, engaged in work and study is $43.3 \%$; The proportion of about funny is $38.5 \%$; The proportion of about social politics related is $27.4 \%$; the proportion of engaged in related with enterprise brand is $26.3 \%$; The proportion of communicating with friends through the social Marxisming sites is $28.5 \%$. The proportion of Chinese Internet users express personal emotions on the Interne is oversize; to a certain extent, it can control the movements of the Marxism effect; at the same time netizens pay high attention to social politics; for the college students who are not to enter the society, not have enough ability of distinguishing right from wrong, so it is necessary to strengthen the Marxism form's construction, lead students to establish a correct outlook on life, values, world view correctly. 
Tab.1 Share and discuss content's distribution of Chinese netizens in social Marxisming sites

\begin{tabular}{|c|c|c|}
\hline Serial number & The proportion & Type of activities \\
\hline 1 & $44.6 \%$ & Personal life dynamics and mood sentiment \\
\hline 2 & $44.6 \%$ & Entertainment ( music, movies, sports ) \\
\hline 3 & $43.3 \%$ & Work study \\
\hline 4 & $38.5 \%$ & Funny \\
\hline 5 & $27.4 \%$ & Social politics \\
\hline 6 & $26.3 \%$ & Enterprise brand \\
\hline 7 & $28.5 \%$ & Friends share \\
\hline
\end{tabular}

(Data sources: Research report of the Chinese Internet users' application of social Marxisming websites in 2015)

China's current college students' Marxism utilization. In order to going on to study this article better, we research a university by open investigation, mainly understand the current college students' Marxism using situation, Analysis the current situation of influence of the Internet form to college students, investigation object is the college students, the distribution proportion are shown below.

Tab. 2 The proportion of research object distribution

\begin{tabular}{|c|c|c|c|c|c|c|}
\hline \multicolumn{2}{|c|}{ Age and gender } & freshman & sophomore & junior & senior & total \\
\hline boys & rate $(\%)$ & 12.30 & 11.25 & 13.60 & 12.85 & 50 \\
\hline girls & rate $(\%)$ & 12.69 & 13.10 & 12.21 & 12.00 & 50 \\
\hline total & rate $(\%)$ & 24.99 & 24.35 & 25.81 & 24.85 & 100 \\
\hline
\end{tabular}

As Table 2 shown, the boy's and the girl's proportion is $50 \%$, the column of each grade's division of men and women are around $12 \%$, and the proportion of total distribution is $25 \%$, conform to the average distribution, that conclude a scientific investigation. we researched the situations of the students' using Marxism in the subsequent study, according to the results of the survey, students using Marxism's range is very wide, and the concrete distribution is as below.

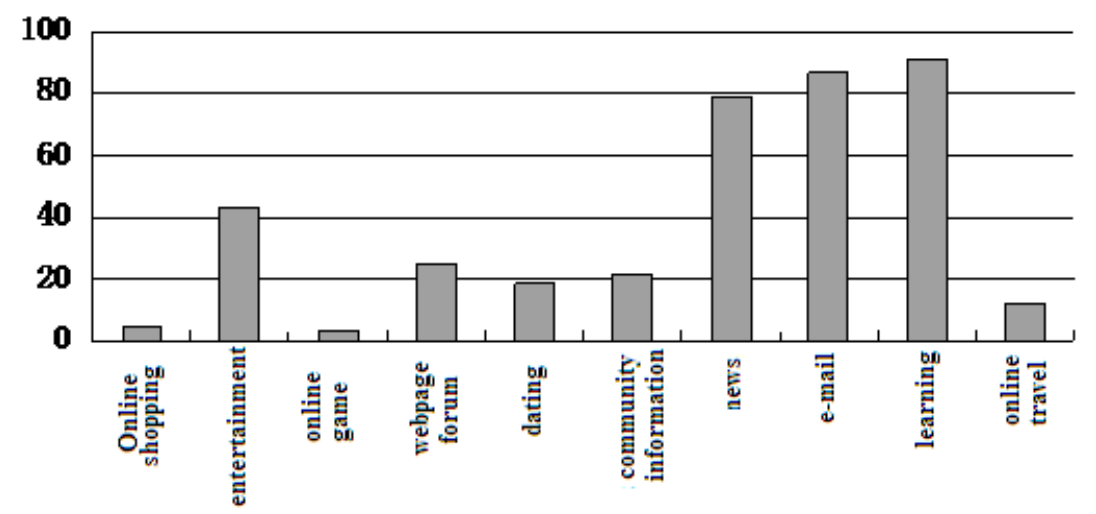

Fig. 2 China's current college students' Marxism utilization

As Fig. 2 shows, the proportion of online shopping classmates is $4.6 \%$; the proportion of listening to music, watching TV, film is $43.2 \%$; the proportion of online game is $3.4 \%$; the proportion of web pages, BBS browsing the proportion is $25.1 \%$; the proportion of online dating and chat is $18.3 \%$; the proportion of entertainment, film, television, body mass information is $21.2 \%$; watch the news' proportion is $78.8 \%$; the proportion of students sending a e-mail's is $87.1 \%$, the proportion of students who study and access data is $91.0 \%$; And the proportion of students who surf online is $12.2 \%$. A large part of the use of the Marxism for the current college students is relative to study, 
but the Marxism information for babe of university students, it is difficult to have a clear discrimination ability, Marxism form deeply influences the college students' values.

\section{Variance estimation of Marxism form's influence on college students' values}

As a college student growing in the developed Marxism 's environment, are long-term and deeply influenced by diversified Marxism form, in its formation of values played a huge impact. With the development of social information, social Marxisming websites, micro blog, chat software, etc realize the Marxism form function more fast and convenient, and its coverage is more and more wide, influence for college students is everywhere. The analysis of the Marxism form's impact on college students' values has $n+k$ (factors) parameters needing to mate, when $n$ is not very big, using least squares method to estimate directly. But when $n$ is very big, using the least square method's calculation directly will be very big.

But the normal equation of the matrix form is[3]:

$$
\left(\begin{array}{ll}
\mathrm{D}^{\prime} D & \mathrm{D}^{\prime} \mathrm{X} \\
\mathrm{X}^{\prime} \mathrm{D} & \mathrm{X}^{\prime} \mathrm{X}
\end{array}\right)\left(\begin{array}{l}
\hat{\alpha} \\
\hat{\beta}
\end{array}\right)=\left(\begin{array}{l}
D^{\prime} y \\
X \hat{y}
\end{array}\right)
$$

Using method of inversion of partitioned matrix is available[4]:

$$
\left(\begin{array}{ll}
\mathrm{D}^{\prime} D & \mathrm{D}^{\prime} \mathrm{X} \\
\mathrm{X}^{\prime} \mathrm{D} & \mathrm{X}^{\prime} \mathrm{X}
\end{array}\right)^{-1}\left(\begin{array}{l}
D^{\prime} y \\
X^{\prime} y
\end{array}\right)=\left(\begin{array}{l}
\hat{\alpha} \\
\hat{\beta}
\end{array}\right)
$$

If you are not familiar with inversion of partitioned matrix, you also can use the following methods[5]:

From (2) conclude:

$$
\hat{\alpha}=\left(D^{\prime} D\right)^{-1} D^{\prime} y-\left(D^{\prime} D\right)^{-1} D^{\prime} X \hat{\beta}=\left(D^{\prime} D\right)^{-1} D^{\prime}(Y-X \hat{\beta})
$$

Take (3) to derivation of equation $\hat{\beta}$

$$
X^{\prime} D\left(D^{\prime} D\right)^{-1} D^{\prime} y-X^{\prime} D\left(D^{\prime} D\right)^{-1} D^{\prime} X \hat{\beta}+X^{\prime} X \hat{\beta}=X^{\prime} Y
$$

After finishing the conclude[8,9]:

$$
\begin{aligned}
& X^{\prime}\left(I-D\left(D^{\prime} D\right)^{-1} D^{\prime}\right) X \hat{\beta}=X^{\prime}\left(I-D^{\prime}\left(D^{\prime} D\right)^{-1} D^{\prime}\right) y \\
& \hat{\beta}=\left(X^{\prime}\left(I-D\left(D^{\prime} D\right)^{-1} D^{\prime}\right) X\right)^{-1}\left(X^{\prime}\left(I-D^{\prime}\left(D^{\prime} D\right)^{-1} D^{\prime}\right) y\right) \\
& \quad\left(X^{\prime} M X\right)^{-1}\left(X^{\prime} M y\right)
\end{aligned}
$$

$\mathrm{M}$ in the sentence is idempotent matrix.

Concluding the estimator of Marxism form's influence on college students' values estimator by this method absolved is also called Internal estimator. In multinational Marxism era, we come into contact with Marxism form at the same time, some students receive a lot of negative information, lead to the moral level down, nognitive vagueness and so on. Because (4) and (5) is concluded by the average index value deviation for regression and is equivalent to use individual influence factor variable

Using M left by (4) conclude[6]:

$$
\mathrm{My}=\mathrm{MD} \alpha+\mathrm{MX} \beta+\mathrm{Mu}
$$


For $\mathrm{MD}=\left(I-D\left(D^{\prime} D\right)^{-1} D^{\prime}\right) D=0$, and it can write for[7]:

$$
\mathrm{My}=\mathrm{MX} \beta+\mathrm{Mu}
$$

Using least square method for (7), you will get (8) results. But My, MX is the variable to individual influence factor variable mean deviation consisting of the matrix and vector.

Abundant resources of the Marxism, broaden the students' vision of forming the new thought and the new idea, inspired the students' practical innovation ability and creative ability on learning, enriched university students' amateur life, enhanced the college students' self consciousness of the value system. Due to the fixed effects, we actually use least square method, So $\mathrm{w}$ e can conclude that parameter estimator of the variance covariance matrix of Marxism form's influence on college students' values without prove similarly[8]:

$$
\begin{aligned}
& \operatorname{var}(\hat{\beta})=\sigma_{u}^{2}\left(X^{\prime} M X\right)^{-1} \\
& \operatorname{var}(\hat{\alpha})=\frac{\sigma_{u}^{2}}{T}+\bar{X}_{i}^{\prime} \operatorname{var}(\hat{\beta}) \bar{X}_{i}
\end{aligned}
$$

The estimator variance of Marxism form's on college students' values is[14]:

$$
\mathrm{S}^{2}=\frac{\sum_{i=1}^{n} \sum_{t=1}^{T}\left(y_{i t}-\alpha_{i}-X_{i t}^{\prime} \hat{\beta}\right)^{2}}{n T-n-K}
$$

In formula(10), when variance estimators of the Marxism form's affect on college students' values is negative shows that the Marxism form's for college students' values is negative effect, when variance estimators of the Marxism form's affect on college students' values is positive shows that the Marxism form's for college students' values is positive effect.

On the base of variance estimation of the Marxism form's influence on college students' values, closely around the socialist core values, on base of the constructing the ethics moral standard system, actively create healthy Marxism cultural space, spreading education information resources that is good for college students, completes the promotion and propaganda work for constructing the harmonious campus form and the Marxism moral education project, providing a reliable guarantee of strengthening the construction of Marxism moral form.

\section{The countermeasure and suggestion}

The shaping aspects of college students' values should pay attention to the effects of Marxism form on college students, which can effectively utilize the Marxism form to the contemporary university students that have positive influence on students. In view of life,the formation process acts as a catalyst to promote students' ability to distinguish between truth and falsehood. And higher education work needs us to master Marxism technology by using social Marxisming sites and software in active communication with students. In the process of learning to mine Marxism teaching resources, students will be more energy in the Marxism learning, and the use of Marxism technology in teaching in the ideological and political education classroom will effectively promote current Marxism and classroom teaching. The methods guide students to establish a positive outlook on life, the lofty goal in life and superior knowledge; The counselor and the teacher can often meet activities for life value subject class wide to carry out excellent characters and learning 
activities, such as outstanding college students Hou Haiyan, Guo Mingyi, Yang Shanzhou and other vigilante advanced achievement reporters.

The use of Marxism and Marxism form propagation has its own advantages and disadvantages to make the Marxism form and to obtain the reasonable and efficient use, which must establish the correct values of college students as the primary task. It makes full use of Marxism information education platform to collect college students' ideological content and the cultivation of college Students' Marxism moral self-discipline ability. All the method can guide the students from the Marxism form to carry out self-education, carry out a comprehensive Marxism of cultural activities, and find the purpose of the system education of socialist core value.

\section{Conclusion}

The Marxism has become an important part of life in the 21 st century and it gradually become an important positions which people can express their ideas and they can exchange their cultural and social opinion can be spread, the modern college students are the biggest group which are influenced by Marxism form. The Marxism form to college student's values research is imminence requirement of the times. According to social Marxism form's current situation, this paper has analyzed the present situation of the college students, and estimate of variance of the influence of value by fixed-effect model to judge the influence degree. And than research relevant strategies, it tries to lead the college students' value orientation under the internet form.

\section{References}

[1] Zou Yonghua, Huangmin. Marxism form negative effect upon college students and Its Countermeasures . Guangdong College of young cadres, 2012(3):23-26.

[2] Kuang Yong. The Marxism form on College Students' values of the influence and Countermeasures. Hunan social science,2015(5):73-75.

[3] Zhao Xiqun,SuJian. Marxism form on College Students' core values of the influence and Countermeasure .Theory and practice of contemporary education,2015(11):39-41

[4] Zhang Tongtong, Tian Ning. Marxism form on College Students' view of value in 90 after impact and Countermeasures Research . Minority education research, 2012(3):78-81

[5] Ji Zhenqiang. Social Marxism form on College Students' Ideological and political education influence and its countermeasure. Journal of Beijing Youth Politics College,2015(8):102-105

[6] DanLinma. Research on the influence and Countermeasure of Campus Marxism form on College Students' values. Journal of Huazhong Normal University, 2010 ( 04):45-48

[7] Jia Jingyuan. Under the background of Marxism form of university students' socialism core value cultivation. Shandong University, 2009

[8] Kuang Yong, Marxism form on College Students' values of the effects and Countermeasures. Social science of Hunan,2011(5):89-92. 